\title{
فاعلية برنامج موسيقى قائم على بعض حلقات المسلسل التليفزيونى أجحل الزهور لإكتساب بعض المهارات الموسيقية لطفل الروضة
}

\author{
إعداد \\ أ.م.د/ بلدرية حسن على \\ أستاذ المناهج وطرق التربس المساعد

$$
\text { قسم التربية الموسيقية }
$$ \\ كلية التربية النوعية - جامعة جنوب الوادى التوبله \\ Badriah.hassan@sed.svu.edu.eg \\ أ. د / هلية محمد دندراوى \\ استاذ الصولفيج والايقاع الحركى والارتجال \\ رئيس قسم التربية الموسيقية \\ كلية التربية النوعية - جامعة جنوب الوادى لونية \\ hadia.hassan@sed.svu.edu.eg
}

$$
\begin{aligned}
& \text { أ عبير فاروق محمد سليمان } \\
& \text { باحثة لدرجة الماجستير بقسم العوم التربوية والنفسية }
\end{aligned}
$$

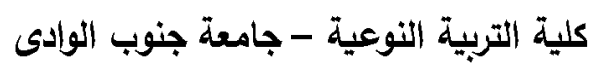

$$
\begin{aligned}
& \text { farabeer011@gmail.com }
\end{aligned}
$$


فاعلية برنامج موسيقى قائم على بعض حلقات المسلسل التليفزيونى أجمل الزهور لإكتساب

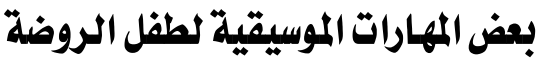

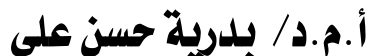

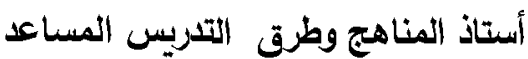

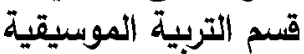

كلية التربية النوعية - جامعة جنوب الوادى التوسية

Badriah.hassan@sed.svu.edu.eg
أ. أد / هلدية محمد دنلدراوى

استاذ الصولفيج والايقاع الحركى والارتجال

رئيس قسم التربية الموسيقية

كلية التربية النوعية - جامعة جنوب الوادئ الوسية hadia.hassan@sed.svu.edu.eg

\section{أ أ/ عبير فاروق محملد سليمان}

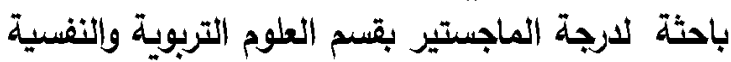

كلية التربية النوعية - جامعة جنوب الواديى التوبه

farabeer011@gmail.com

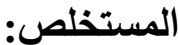

يهذف البحث الحالى إلى التعرف على فاعلية برنامج موسيقى قائم على بعض حلقات

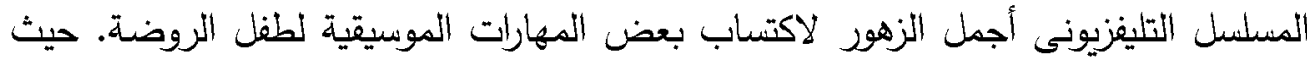

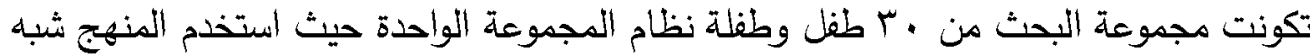
التجرببى لما ينظمه من تت اول متغيرات منتقلة ومتغيرات تابعة حيث تجرى تعديلات محددة

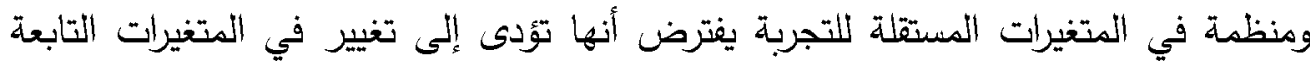
وذلك عن طريق القياس التبلى والبعدى والتتبعى وذلك لملائمة طبيعة البحث الحالى. وتم إعداد قائمة خاصة بالمهارات الموسيقية وبطاقة ملاحظة خاصة بالمهارات الموسيقية وهذه

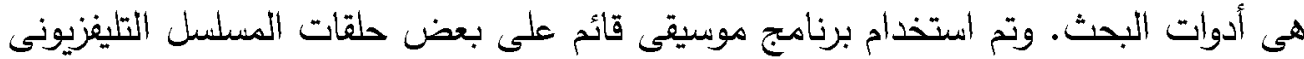

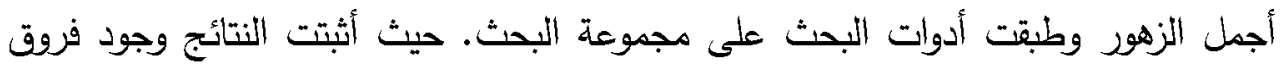
ذات دلالة إحصائية بين متوسطات درجات أفراد المجموعة التجريبية على بطاقة ملاحظة

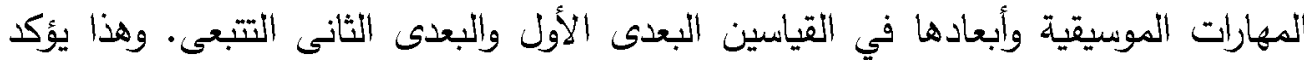

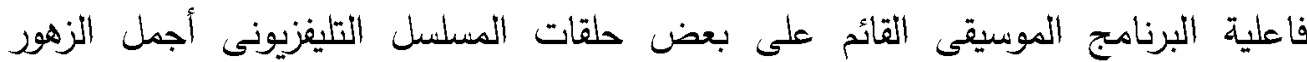
لإكتساب بعض المهارات الموسيقية لطفل الروضة. وجاءت توصيات البحث بضرورة تطبيق البرني البرنامج الموسيقى القائم على بعض حلقات المسلسل التليغزيونى أجمل الزهور على مراحل تعليمية مختلفة .

الكلمات المفتاحية : برامج الأطفال التليفزيونية - المهارات الموسيقية - مرحلة رياض

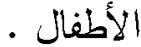




\section{The effectiveness of a music program based on some episodes of the t.v. series " the most beautiful flowers " to teach some musical skills for the kindergarten kid}

\author{
Prof.Dr.Hedeya Mohamed Dndrawy \\ Department of Music Education \\ Faculty of Special Education \\ South Valley Unversity \\ Badriah.hassan@sed.svu.edu.eg
}

\author{
Ass.Prof. Badriah Hassan Ali \\ Department of Music Education \\ Faculty of Special Education \\ South Valley Unversity \\ hadia.hassan@sed.svu.edu.eg
}

\section{Abeer Farouk Mohamed Soliman}

Researcher for a master's degree, Department of

Educational and Psychologica

Faculty of Special Education - South Valley Unversity

farabeer011@gmail.com

\section{Abstract :}

This study aimed to identify the effectiveness of a music program based on some episodes of the t.v. series " the most beautiful flowers " to teach some musical skills for the kindergarten kid. The research group consisted of 30 male and female in one group. Where the semi-experimental approach was used because it regulates the treatment of independent and dependent variables، where specific and organized adjustments are made in the independent variables of the experiment and it is assumed that it leads to a change in dependent variables by way of pre-and post-sequencing measurement to suit the nature of the current research. A list of musical skills and a note for musical skills have been prepared، and these are the research tools. A music program based on some episodes of the t.v. series " the most beautiful flowers " was used، and research tools were applied to the research group.Where the results demonstrated the presence of statistically significant differences between the mean scores of the members of the control group and the degrees of the members of the experimental group on the note card of musical skills and their dimensions in the telemetry measurement in favor of the experimental group The results also demonstrated that there were no statistically significant differences between the mean scores of the experimental group on the note card of musical skills and their dimensions in the first and post-second track measurements. This confirms the effectiveness of the music program' which is based on some episodes of the t.v. series " the most beautiful flowers " to teach some musical skills for the kindergarten kid. The recommendations of this study came to the necessity of applying the music program based on some episodes of the t.v. series " the most beautiful flowers " on different educational stages.

Keywords : children's television programs - musical skills - Kindergarten stage 
يعد الطفل الركيزة الأساسية فى بناء المجتمع وتقدمه حيث توضع عليه أمال وطموحات تدفع الباحثين إلى مزيد من الجها والاهتمام بتربيته وتعليمه ليحقق النمو المتكامل في جميع الجوانب الجسمية والعقلية والوجدانية والانفعالية والاجتماعية ليصبح إنسانا مسئولا وعضوا فعال فى بناء مجتمعه لذلك فالتنشئة الأولى له التى يشترك فيها معظم مؤسسات المجتمع المختلفة لها الدور الرئيس فى تكوين ملامح شخصيته ولهيا يبذل المختصون قصارى جهدهم فى تقديم المفاهيم والمبادئ الأساسية التى تناسب

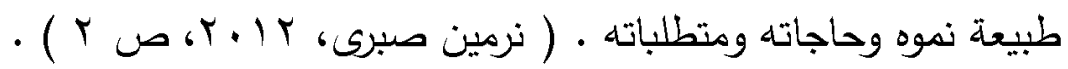
وتعد أنشطة التربية الموسيقية من أهم الوسائل الفعالة للتربية الحديثة لما لها من لهن أهمية خاصدة فى حياة الطفل لكونها احد الوسائل الناجحة فى تثكيل الطفل روحيا وعقليا وجسديا فهى تلعب دورا هاما فى بناء شخصيته منذ طفولته . ( أسامة

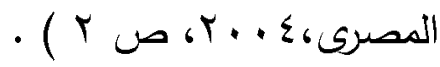

فالتربية الموسيقية تسهم بشكل فعال فى تنمية قدرة الطفل على التحكم والتكيف مع البيئة المحيطة به حيث تؤثر الأنشطة الموسيقية المختلفة ( الأغنية - الألعاب الموسيقية الحركية - القصة الموسيقية الحركية - الاستماع والتذوق - الابتكار - آلات البآند الإيقاعية ) على ميول الطفل وأحاسيسه حيث أنها أدوات تربوية تساعد الطفل فى النمو الثامل لشخصيته فى جميع الجوانب كما أنها تعمل على إضفاء روح السعادة على حياته . ( جيلان أحمد عبد القادر، ( .. r، ص 11) .

ويؤثر اكتساب مهارات التربية الموسيقية على تنمية النواحى الجسمية والنفسية والعقلية والعضلية والذاكرة حتى النواحى الجمالية لدى المتعمين بصفة عامة حيث تنمى مهارتى العزف والايقاع الحركى كلا من التوافق العضلى والعصبى والفكرى وكذلك التركيز والذاكرة وتنمى مهارة التذوق الموسيقى الناحية الجمالية والذوق العام 
وتضبط الانفعالات النفسية أما مهارة الغناء الفردى والجماعى فهى تنمى القدرة على الغناء المرتبط بعملية التتف وإخراج الصوت السليم المدرب وأيضا تنمى روح التعاون

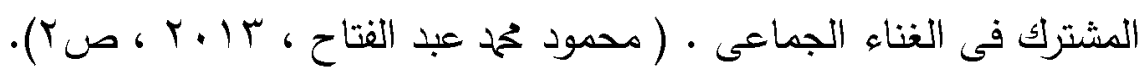

ومن خلال الملاحظة المتأنية من قبل المهتمين بالعملية التعليمية لبعض الوسائل السمعية البصرية ( التليزيون ) الثاثة الصغيرة استدعى اهتمامهم بالتليفزيون وبرامجه التى أصبح يتحدث عنها العام والخاص لما لها من تأثير كبير على المجتمع

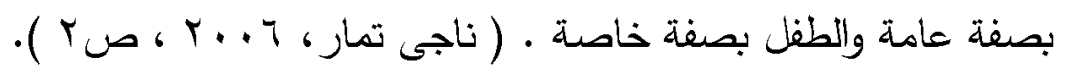
حيث يؤثز التليغزيون على الطفل بشكل قوى ومباشر فهو يعد من أكبر مصادر الخبرة فى حياته حيث أنه يشارك فى شتى العمليات التزبوية بما يقدمه من برامج يستطيع الوصول إلى الأطفال قى أعمار مبكرة وبكثافة عالية فالأطفال من أكثر الفئات العمرية اهتماما بمثاهدة التليفزيون وهو أحد المؤسسات الثقافية المهمة فى المجتمع وتهدف برامجه المتتوعة إلى تعديل سلوك مشاهديه على اختلاف أنواعهم من حيث العمر الزمنى ومستوى التعليم بينهم وإكسابهم أنماطا جديدة من السلوك نتيجة لقضاء

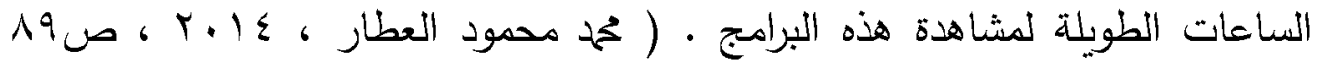
$\cdot(9 \cdot 6$

فالبرامج والمسلسلات التليفزيونية الخاصة بالأطفال متنوعة وتشمل معظم نواحى الحياء الاجتماعية والاقتصادية والسياسية والدينية والثقافية والرياضية وتخاطب جميع الفئات العمرية منها مرحلة الطفولة فهناك برامج تعليمية موجهة للأطفال بإختلاف مراحل الطفولة وبرامج ثقافية وأخرى ترفيهية وإعلامية وإخبارية واجتماعية وبرامج للهواة 
والفنون على اختلاف ألوانها كلها تؤثر على النمو الاجتماعى للأطفال وفى كيانهم

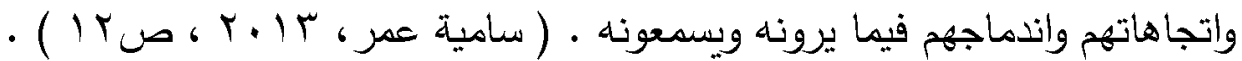

ومن هذا المنطلق فإن عددا هن البرامج والمسلسلات التلفزيونية الخاصة

بالأطفال تقدم فوائد عدة من منها التكوين العمى والاجتماعى والثقافى للطفل إضافة إلى إثراء فكر الطفل وحسه ورصيده اللغوى وتتمية القدرات الإبداعية والمهارات الأدائية لايه وإلقاء الضوء على الهوايات والرغبات التى تشبع كثيرا من حاجاته وتطلعاته وتتمية المواهب والتشجيع على إظهار الميول والاتجاهات والنظر للحياة . ( على تعوينات ،

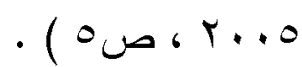

ومن المسلسلات التلفزيونية التى توجه إلى الأطفال مسلسل زهور من نور ومسلسل جدو عبدو زارع أرضه ومسلسل كوكى كاك أما بالنسبة لمسلسل أجمل الزهور والذى كان من إخراج مجيدة نجم وتأليف شنودة جرجس فهو احد المسلسلات

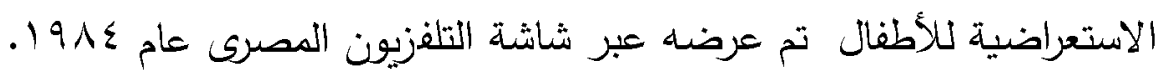

\section{htho://wuw.dostor.org /}

ونظراً لأن مرحلة الطفولة تتسم بقلة الخبرة لدى الأطفال يقابلها حب الاستكثاف والاستطلاع يجعل ذلك فرصة التلفاز كبيرة فى تزويد الأطفال بأكبر قدر من المعرفة

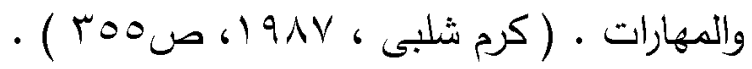




$$
\text { أكدت كثير من الدراسات والبحوث أمثال : }
$$

- Grimes \& Others ( 2004) ، Stephen,K and Stewart,K (2000)

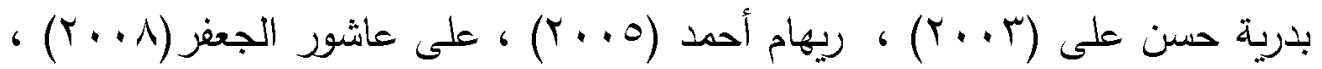

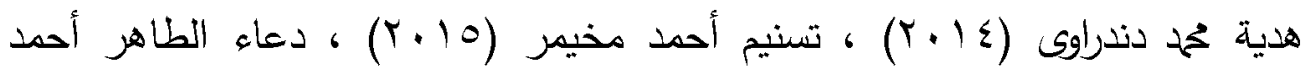

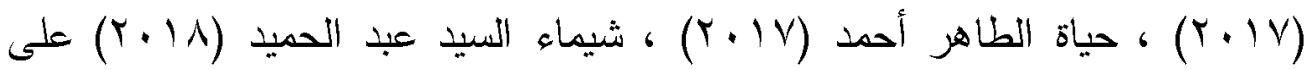
الاهتمام بالطفل من النواحى الاجتماعية والنفسية وذلك من خلال الأنثطة الموسيقية

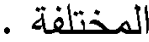

ومن خلال مشاهدة الباحثة لمسلسل أجمل الزهور عبر شاشة التلفزيون المصرى تبين احتواء حلقات هذا المسلسل على العديد من الأنشطة الموسيقية من أغنية وقصه التهائ ولعبه وغيرها من الأنشطة الموسيقية المختلفة لذلك رأت الباحثة ضرورة إلقاء الضوء على هذه الحقات للنهوض بعناصر التربية الموسيقية لطفل رياض الأطفال من خلال تدريس بعض بنود التربية الموسيقية لأطفال الروضة .

وبعد إطلاع الباحثة على العديد من الدراسات السابقة المنشور منها والغير المنشور والمرتبطة بمو ضوع البحث ارتباطُ مباشرا قد تم ترتيهم من القديم الى الحديث

ا. دراسة ( Stephen,K and Stewart,K ، 2000 ) بعنوان : " تأثير البرامج التى تعرضها القنوات التلفزيونية الفضائية التى تتضمن العدوانية والعنف على

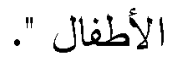

r. دراسة ( ع . . T ، Grimes \& Others ) بعنوان : " تأثير مشاهدة برامج العنف التليفزيونية على تفاقم الأمراض النفسية للى الأطفال " . 
r. دراسة ( بدرية حسن على ، r. . r ) بعنوان : " فعالية برنامج مقترح فى التربية الموسيقية على تعديل بعض العادات السلوكية غير المرغوب فيها لاى أطفال

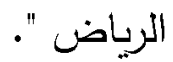

ع. دراسة ( ريهام أحمد ، 0. . ب ) بعنوان : " تأثير التعرض لبرامج التلفزيون المقدمة لطفل ما قبل المدرسة على اكتسابه المهارات اللغوية ". ه. دراسة ( على عاشور الجعز ، A . . ب ) بعنوان : " البرامج الفضائية لدى عينة من الأطفال بدولة الكويت وعلاقتها بالتفكير الخلقى ".

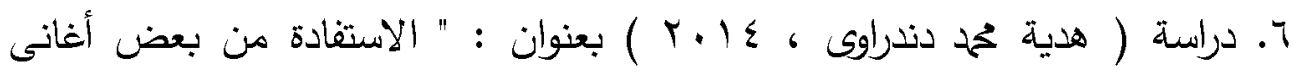
وحواديت أبلة فضيلة فى تنمية بعض القيم التربوية وبعض المفاهيم الموسيقية لطفل مرحلة رياض الأطفال ". V. دراسة ( تسنيم أحمد مخيمر ، 10 + r ) ) " القيم فى برامج الأطفال التليفزيونية برامج قناة إم بى سى نموذجاً : دراسة تحليلية " .

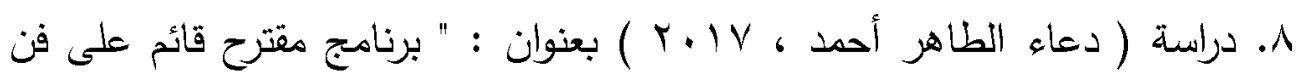
المسرح لتنمية بعض المهارات الموسيقية والاجتماعية لدى طفل الروضة ". 9. دراسة ( حياة الطاهر أحمد ، Y V. V ) بعنوان : " دور برامج الأطفال التليزيونية فى دعم القيم التربوية والسلوكية : دراسة وصفية تحليلية بالتطبيق على برنامج قطار الزهور بقناة الشروق الفضائية".

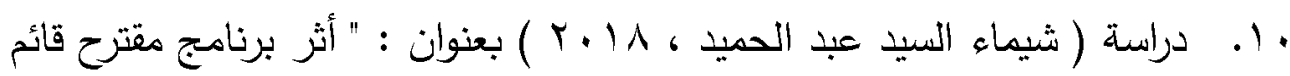
على استراتيجية التعلم التعاونى لتنمية بعض المهارات الموسيقية والاجتماعية لاى تلاميذ المرحلة الإبتدائية ". أسئلة البحث : 
من خلال العرض السابق لمشكلة البحث تم تحديد الأسئلة كما يلى : 1- ما المهارات الموسيقية المتضمنة فى بعض حلقات مسلسل أجمل الزهور؟ r- ما فاعلية البرنامج الموسيقى القائم على بعض حلقات مسلسل أجمل الزهور لاكتساب بعض المهارات

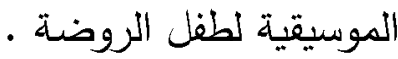
أهداف البحث :

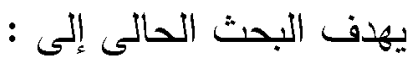
1- إلقاء الضوء على بعض حلقات المسلسل التليفزيونى أجمل الزهور . r- النهوض ببعض عناصر التربية الموسيقية لاى طفل مرحلة رياض الأطفال . r- قياس فاعلية البرنامج القائم على بعض حلقات مسلسل أجمل الزهور في اكتساب لئل بعض المهارات الموسيقية لطفل الروضة . محددات البحث :

يقتصر البحث الحالى على بعض المحدات التالية : ا- محدد بشرى : مجموعة من أطفال الروضة بالمستوى الثانى (KGY) حيث بلغ عددهم ( • r ) طفل وطفلة . r- محدد مكانى : محافظة قنا - حضانة Bright Kids الخاصة للغات .

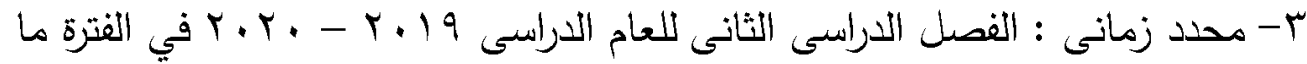

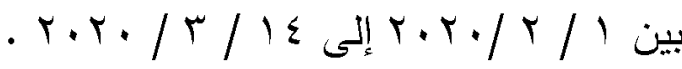

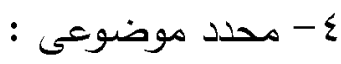

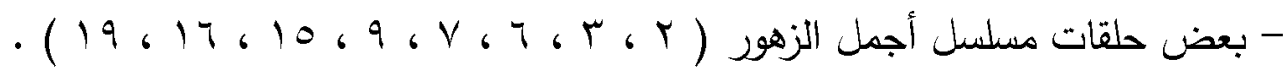

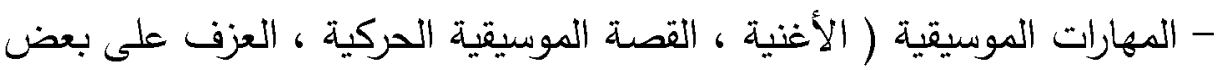
آلات الباند الإيقاعية ، الابتكار ) .

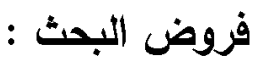
1- توجد فروق ذات دلالة إحصائية بين متوسطات درجات أفراد المجموعة فى 
التطبيق القبلى والبعدى الأول لبطاقة ملاحظة المهارات الموسيقية وأبعادها لصالح

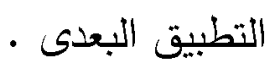

r- لا توجد فروق ذات دلالة إحصائية بين متوسطات درجات أفراد المجموعة فى التطبيق البعدى الأول والبعدى الثانى التتبعى لبطاقة ملاحظة المهارات الموسيقية وأبعادها مصطلحات البحث :

فاعلية : تعرف إجرائيا " أنها مدى تحقيق بعض المهارات الموسيقية والقيم التربوية المطلوبة من البرنامج بمستوى الإتقان من خلال سلوكهم ودرجاتهم فى الاختبار البعدى

برنامج: يعرف اجزائيا " بأنه مخطط متناسق العناصر من الأهداف والوسائل والمحتوى والأنشطة التعليمية والأدوات وأساليب التقويم وتكون بطريقة مترابطة ومعد مسبقا لغرض التعليم او التدريب ".

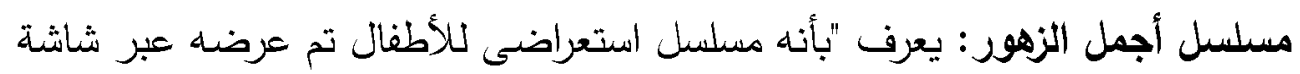
التلفزيون المصرى عام (ع^ه 1 ) تأليف شنودة جرجس وإخراج مجيدة نجم ومن أبطال العمل نجوى إبراهيم وعبد الرحمن أبو زهرة " .

\section{/https://www.elcinema.com/work/2035835}

المهارات الموسيقية: تعرف إجرائيا " هى الارجة التى يحصل عليها أفراد العينة فى بطاقة ملاحظة المهارات الموسيقية " .

$$
\text { أهمية البحث : n }
$$

1 - بلنسبة للطفل : يعد البحث الحالى بمثابة محاولة لإكساب بعض المهارات الموسيقية المناسبة لطفل الروضة من خلال مسلسل أجمل الزهور . r- بالنسبة لمعلمات رياض الأطفال :يعد البحث الحالى بمثابة محاولة لمساعدة معلمة 
الروضة فى إنتقاء المهارات الموسيقية المناسبة لهذه المرحلة.

r- بالنسبة لأولياء الأمور: بيان دور التربية الموسيقية وأثرها على الأطفال تربويا وتعليميا، استخدام أولياء الأمور الأغانى والقصة الموسيقية الحركية وتوظيفهما في حياء الطفل.

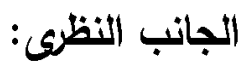
أولاً : برامج الأطفال التليفزيونية:

\section{• عبريف برامج الأطفال التليفزيونية :}

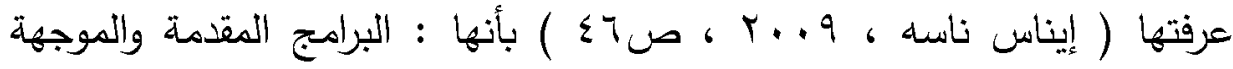
لأطفال وتتخذ أشكالاً وقوالب فنية عديدة منها الحديث المباشر والحوار والمناقشة كى تحقق أهدافها فى الوصول إلى جماهيرها المستهدفة . وعرفها ( ادوارد ستاشيف ورودى بريتز ، د.ت ، ص77 ) بأنها : هى البرامج التى تعرض خصيصاً للأطفال مثل برامج المسابقات وأفلام الرسوم المتحركة وأفلام الكارتون وبرامج هدايا الأطفال وكل ما يبعث فيهم المتعة والفرح • وتعرف إجرائياً بأنها : هى كل ما يبثه التليفزيون من برامج للأطفال سواء كانت ترفيهية ، تثقيفية ، تربوية ، وهذه البرامج تغرس فيهم القيم والسلوك والمهارات وتعلم الأطفال كيفية الإندماج مع الحياء الاجتماعية بكل أثكالها .

\section{أهمية ووظيفة برامج الأطفال التليفزيونية :}

تتمثل الوظيفة الأساسية للبرامج التليفزيونية الموجهة نحو الطفل فى تربية الطفل بطريقة تختلف عن التى تتخذها المدرسة أو يتخذها المنزل من جمع المعلومات 
وإصدار الإرشادات والتعليمات والتوصيات بأسلوب مباشر والتربية هنا تشمل كافة ألوان التربية من تربية صحية أو نفسية أو عقلية أو روحية . ( منير فتح الله ، م. . . ، - (

كما تقدم تلك البرامج لتحقيق أهداف معينة منها : 1- إكساب الأطفال المفاهيم والمعارف والمعلومات والمهارات والخبرات . r- جذب انتباه الأطفال نحو اتجاهات وسلوكيات وقيم مرغوبة . r- تشكيل السمات التربوية لشخصية الطفل . ع- غرس المفاهيم الأخلافية والتربوية والاجتماعية والثقاقية فى نفوس الأطفال . ه- من المصادر المهمة التى يمكن توظيفها فى تثقيف الأطفال عامة وطفل الروضة خاصة . 4- تشكيل أذهان ونفسيات الأطفال بعيداً عن نطاق التعليم المدرسى • ( عمح عوض ،

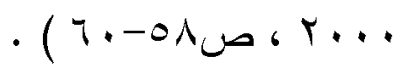

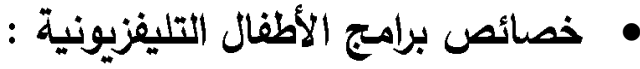

تقتنى برامج الأطفال التليزيونية جملة من الخصـائص التى تؤهلها لأداء رسالتها بنج 1- الجاذبية : وتكمن فى مخاطبة هذه البراهج لحواس الطفل كحاسـة السمع والبصر وما تعرضه الصورة المرئية من أشكال ورموز ومضامين يتشرب منها الطفل العديد من

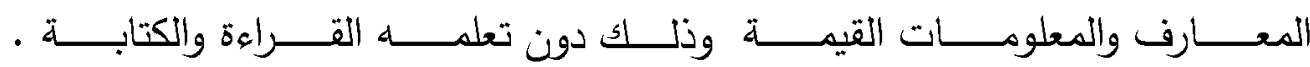
r- الأختيارية أو الطواعية : حيث يستطيع الطفل مشاهدة البرامج المفضلة لديه بحريـة 


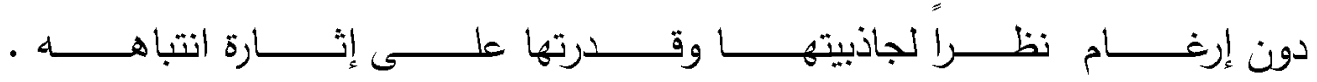
r- الفورية : ويقصد بها قدرة هذه البرامج على التوافر فى جميع الأماكن التى يريدها الطفل ويفضلها ـ ـ - سهولة الاستخدام : حيث يستطيع الطفل استخدام برامج الأطفال التليززيونية والإستفادة منها بكل سلاستة ويسر مقارنة بوسائل الإتصـال الأخرى التى التى تحتاج المعرفة والاطلاع بمبادئ القراءة والكتابة . - قدرتها على تحقيق عدة مهام للطفل من ترويح وتثقيف وإكسابه العديد من المهارات والاتجاهات الإيجابيـة وخلق . ار متنوع

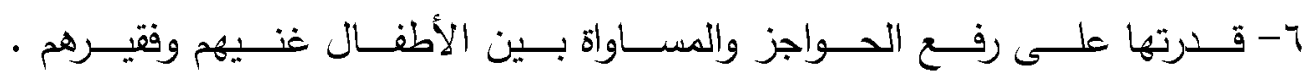
V- تتاولها سلسلة من المتغيرات المرئية والصوتية التى تنسق وتنظم بشكل فنى رائع

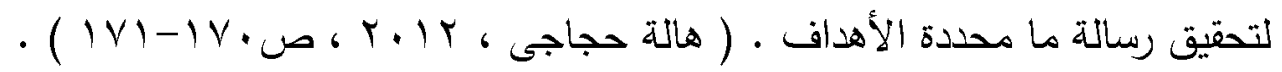
أسس ومعايير برامج الأطفال التليفزيونية : 1- الاهتمام بلغة الطفل ومعجمه اللغوى . r- التركيز على المادة الأدبية من حيث دقة المعلومات وصحتها . r- الاهتمام بمحاكاة القيم والسلوك والخيال . ع- الإستفادة من المؤثرات الصوتية والموسيقى التعبيرية . 0- الإبداع والابتكار فى الثكل والمضمون • ( هيثم يحيى خواجة ، ع ا ـ ، ص

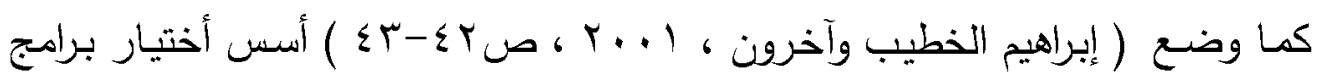
التلفاز المحلية والعالمية الموجهة نحو الطفل ومنها : 
1- اتساع البرنـامج لأنواع أدب الأطفال الملائمـة للتليفزيون مـع مراعاة الخصـائص

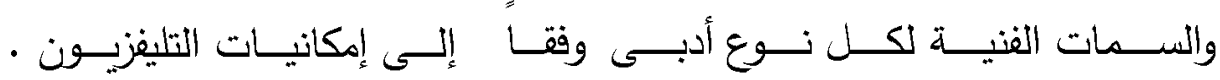
r- استخدام إمكانيات التليفزيون بأسلوب فنى يتناسب مـع مراحل نمو الأطفال كاستعمال الخدع السينمائية والمؤثرات البصرية وانتشار الحركة والنشاط والحيويـة

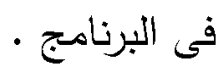

r- استخدام اللغة العربية الفصحة السلسلة والبسيطة بحيث تتناسب مـع قدرات الأطفـال اللغويـة والبعـد عـن اللهجـة المحليـة أو اسـتخدامها فـى أضـيق نطـاق . ع- اتخـاذ خطاً فكرياً واضـحاً وعدم حشر أى مادة حشراً مهما بلغت أهميتها . 0- اختيـار الموضـوعات الخياليـة بثـئ مـن الاقـة والحذر لتحسين ملكـة الخيـال التكوينى عند الأطفال بما لا يعطى الفرصـة للميل نحو التوهم والخيال الهدام • ج- البعد عن النمط التعليمى والخطابى وتواجد نوعين من البرامج إحداهما خاص للأطفال الذين تتراوح أعمارهم بين r-7 سنوات والآخر خاص بأطفال المرحلة

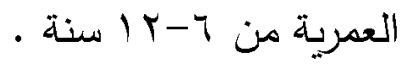

\section{برامج الأطفال فى الفضائيات العربية :}

عن الواقع الحالى لبرامج الأطفال فى الفضائيات العربية نستطيع القول أن الإنتاج التليززيونى المخصص للطفل العربى لا يزال متواضع الحجم والثأن ونتيجة لذلك تلجأ الكتير من القنوات التليزيونية العربية إلى البرامج والأفلام الكرتونية المستوردة وهى فى معظمها بعيدة تماماً عن الثقافة العربية وتحرض الأطفال على العنف وتعلم الخرافة بدلاً من التركيز على المفاهيم التربوية والأخلاقية و تعلم التاريخ المزدهر للحضارة العربية الإسلامية ( وديع محمد سعيد العزعزى ، ع . .ب ، صعـ ) ) . 


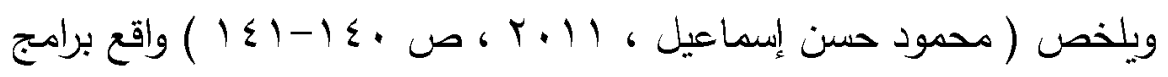

الأطفال فى القنوات العربية فى النقاط التالية : ا - قلة المادة الكرتونية الهادفة والملائمة للأطفال .

r- قلة المنوعات والمسرحيات التربوية التعليمية الهادفة للأطفال . r- قلة الساعات المخصصة لهذه النوعية من البرامج • ع- الإعتماد بنسبة كبيرة على البرامج المستوردة ( أكثر من 0\% ) ) . - الإعتماد في الغالب على أسلوب التوجيه المباشر • ج- تكثيف التصوير فى الأستوديو . - قلة التشويش والإعتماد على النمطية . V ᄉ- الإعتماد على أفلام الكارتون وما تضم من مشاهد غير مرغوبة تؤثر على سلوكيات الطفل .

و- تجاهل الجانب الأخلاقى فى جميع ما يتم بثه من الأفلام الكارتونية الغربية وهى فى أغلبيتها تشغل وقت الطفل وترفه عنه دون جدوى إضافة إلى أنها تحتوى

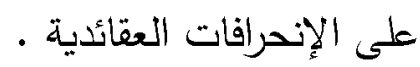
• - شيوع العنف وثقافته فى معظم أفلام الكارتون • ثانياً : المهارات الموسيقية : تعريف المهارة :

عرفها ( فؤاد أبو حطب وأمال صادق ، 1 . . ، ص ص ) بأنها : نشاط معقد يتطلب فترة من التدريب المقصود والممارسة المنظمة والخبرة المضبوطة بحيث يؤدى بطريقة ملائمة - مبة 


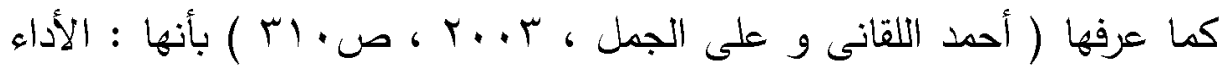
السهل الاقيق القائم على الفهم لما يتعلمه الإنسان حركياً وعقلياً مع توفير الوقت والجها والتكاليف .

وتعرف إجرائيا : بأنها عبارة عن نمط من السلوك يكتسب عن طريق الترربب المقصود والمستمر ومن خلال خبرات منظمة تمكنه من أداء هذا السلوك بسهولة وكفاءة وبدرجة من الاقة والمرونة يعتاده الطفل ويصبح عادة متأصلة لديه .

\section{تعريف المهارات الموسيقية :}

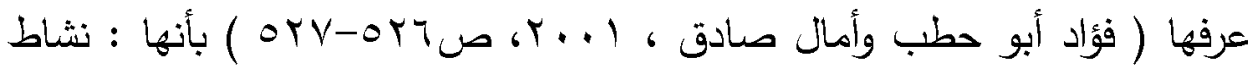
حسى حركى مركب من حركات عضلية متآزرة مع أداء الأصابع •

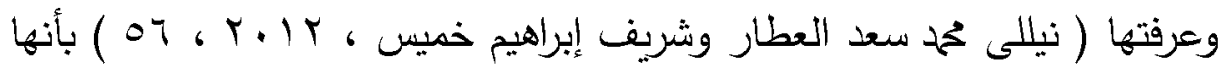
نشاطات تتضمن استخداماً متناسقاً لمجموعة من عضلات الجسم الكبيرة أو الصغيرة . وتعرف إجرائياً : بأنها الدرجة التى يحصل عليها أفراد العينة فى بطاقة ملاحظة المهارات الموسيقية . ت المات

\section{المهارات الموسيقية فى مرحلة الطفولة : \\ أولاً : مهارة القصة الموسيقية الحركية}

تعتبر القصة بشكل عام والقصة الموسيقية الحركية بشكل خاص من الوسائل المفضلة للأطفال حيث تثير الأحداث المتباينة انتباه الطفل لأنها تحتوى على مواقف متلاحقة تجعل الطفل شغوفا لاكتشاف نهايتها ولذلك يعتمد عليها العديد من التربويين 
فى تحقيق أهداف تربوية تعليمية وموسيقية عن طريقها ـ ( هانى إبراهيم الاسوقى ،

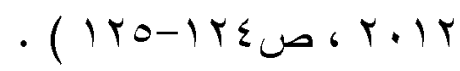

وذلك لما لها من أهمية فى تقديم الكثير من المعلومات والمعارف والسلوكيات القيمة فى سياق ممتع وشيق يتيح للطفل بأن يتجاوب معها ويتقص أدوارها بحيث يصبح من خلالها عنصراً فعالاً داخل مواقفها التعليمية المتنوعة . ( نيللى محمد سعد لئل

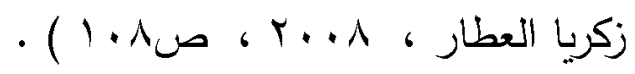

لذلك القصة الموسيقية الحركية أحدى الأساليب المبتكرة لتحقيق العديد من الأهداف حيث أن للقصة الموسيقية وحدة موضوعية وأحداث للبداية والنهاية وما تحتويه من تتابع فى الأفكار وترابط موضوعها بطريقة منطقية تثير وجدان وخيال الطفل فهى توفق بين الرغبة للحركة والغناء والأحداث المتتابعة ـ ( آمال حسين خليل

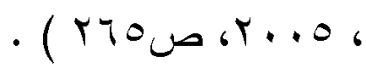

ثاني اً : مهارة الحركة ( الألعاب الموسيقية ) :

يشكل اللعب المقترن بالموسيقى أساس من الأساسيات الضرورية فى حياء الطفل مثل الأكل والنوم والطفل هنا ليس بحاجة إلى تعلم اللعب بل بحاجة إلى التوجيه والتنظيم وقد رأى "دالكروز" أن جسد الطفل يشكل أداء موسيقية وتمثل الحركة لغة هذا الجسد وتوظيفها فى الألعاب توفر للطفل وسيلة للتعلم إلى جانب أنها تتيح له فرصة التعبير عن أحاسيسه ووجدانه عند الاستماع للموسيقى وعند لعبه كما أنها بالنسبة للموسيقى تبين مستوى تعلم الطفل واستيعابه لعناصرها ومكوناتها من خلا الاستجابة الحركية لذلك يستحب فى بداية التعلم الجمع بين الموسيقى والحركة معاً . ( نجلاه

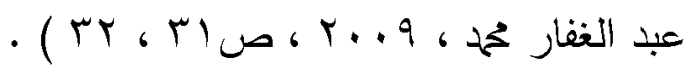




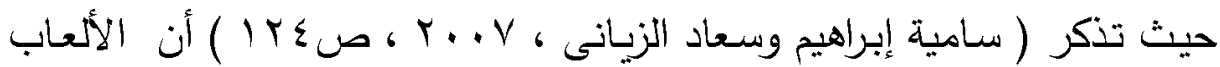
الموسيقية توفق بين رغبة الطفل في الحركة واللعب وبين حبه للموسيقى فهى تتيح للطفل فرصـة التعبير عن نفسـه كما أنها تسـاعد الطفل على النمو السليم لعضـلاته فضلاً عن إكسابه التناغم فى الحركة وهى أيضاً تجدد طاقته وحيويته وتعلب دوراً هاماً فى تكوين خلقه وتقويم سلوكياته حيث يعمل اللعب الجماعى بدوره على نشر التعاون

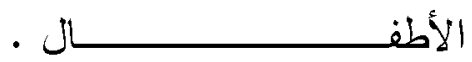
باركة بـ والمش ثالثاً : مهارة الاستماع وإلتذوق :

يعد الاستماع للموسيقى وتذوقها من أهم الأنشطة التى تساهم فى تكوين كافة الخبرات الموسيقية المختلفة والتى تتعلق بالحس السمعى وهو مقدرة عقلية تتطور فى الأطفال بشكل تدريجى عبر مشاركتهم الإيجابية فى مختلف ومتنوع الأنشطة الموسيقية وهو كنشـاطفى مرحلة ربـاض الأطفال يشمل التمييز بين الأداء القوى والأداء

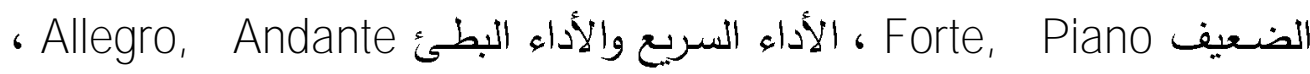
الأصوات الحادة والأصـوات الغليظة High, Low ، الأداء المتصل والأداء المتقطع Legato, Staccato ، اللحن المفرح والحزين Happy, Sad ، ( نيللى تحمد العطار . ( VT מ r...9،

كذلك يؤكد ( Hallam, 2001, P 11 ) أن الأطفال مستمعون رفيعو المستوى وصانعو موسيقى منذ مراحل الطفولة المبكرة والأساليب التى يستوعبون بها الموسيقى تتقدم وتتمو على الدوام وبانتظام • رابعا : مهارة الغناء : مورهي ويعد الغناء من الأنثطة المفضلة للطفل ووسيلة تربوية تعليمية تهذف إلى النهوض بثقافته عبر نقل المعارف القيمة وذلك عن طريث كلمات الأغنية إلى جانب بث الأسس التربوية لديه وغرس خصال حميدة فضلا عن تربية التذوق الفنى لايه 
وتستطيع الأغنية أن تستهوى الطفل وتخلق له عالم محبب إلى وجدانه وإحساسه بل إنها تؤدى دوراً بالغ الأهمية فى تتميته فى جميع الجوانب الجسدية والعقلية والاثفعالية والاجتماعية ولذلك يجب أن تحتوي الأغنية الأهداف التى تساهم فى تتمية هذه

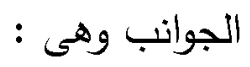

1-زيادة الحصيلة اللغوية لدى الطفل . r- إكساب الطفل المفاهيم التى تعاونه على التعرف على المناسبات والظواهر

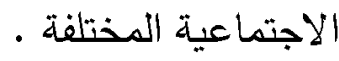

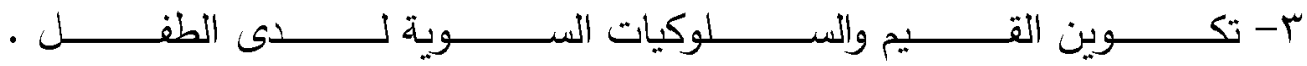
ع- تدريب الطفل على المشاركة الإيجابية داخل الجماعـة والتعاون و الثعور بدوره. ه- تنميـة الذاكرة عبر ربط الأغنيـة بمقررات المنهج المدرسى لكى يكتسب الطفل المعلومـات والمعرفـة بأسـلوب ممتع وحيـوى · ( صـبحى إبراهيم الثـرقاوى وآخرون ،

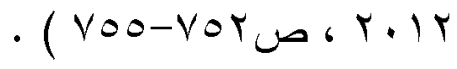

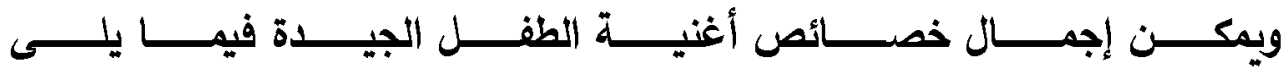
1- أن تكون الأغنية باللغة العربية البسيطة حتى يستطيع الطفل استيعابها وحفظها r- أن تكون كلماتها ممتعـة بسـيطة سـهلة وفـى نطـاق محصـلة الطفل اللغويـة .

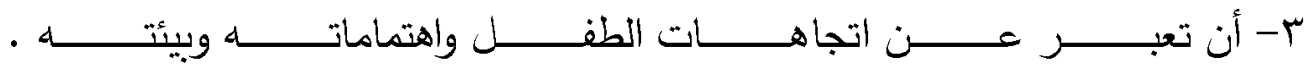

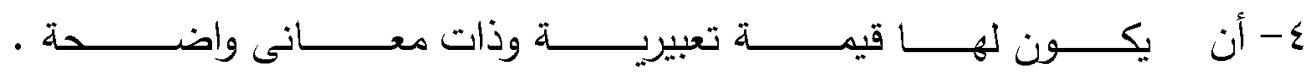
0- أن يتسـ إيقاعها بالبسـاطة والحيويـة والوضـوح وسـرعتها ملاعمـة لخصـائص نمـو الطفل . 
7- أن يكون لحنها فى النطاق الصوتى المناسب لطبيعة صوت الطفل ويكون مدتحا وجذابا يستطيع تذكره وأن تكون عبارات اللحن قصيرة ومكررة لكى يستطيع حفظه. V أن تكون المصاحبة سهلة وبسيطة ولا تطغى على لحن الأغنية الأساسى .

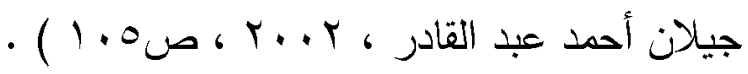
خامساً : مهارة العزف على الآلات الباند الإيقاعية :

يعتبر العزف على الآلات الباند الإيقاعية من أهم ألوان النشاط الموسيقى للى الطفل فهى تتيح له فرصة المشاركة الفعالة في الأداء الموسيقى وتضافره بطريقة غير مباشرة لمعرفة أعمال جيدة من الموسيقى لأن مشاركته فى عزفها يحيطها إليه أكثر من

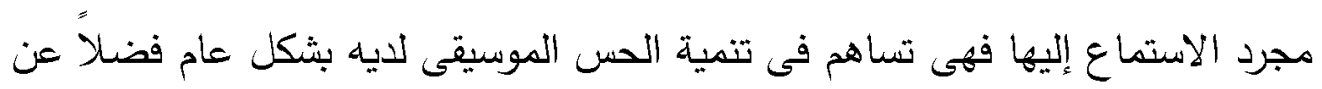
أنها تثير اليقظة والانتباه والتركيز والنظام لاى الأطفال . ( مانيرفا رشدى أمين ،

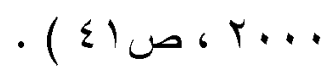

كما يعتبر العزف على الآلات الإيقاعية وسيلة ترفيهية مسلية ومشوقة للأطفال نستطيع عن طريقها تتمية خصائص نمو الطفل المختلفة وفى ذات الوقت تحقيق

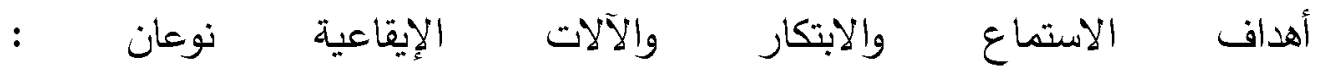

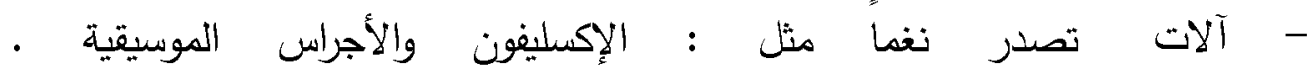
- آلات لا تصدر نغماً مثل : الطبة ، الكاستتيت ، الجلاجل ، الاف وينشأ الصوت

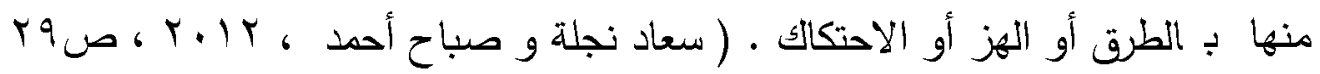
- ( سادسا : مهارة الإنتاج الفنى الابتكارى : 
وهو عبارة عن شكل مستحدث أو إعادة صياغة لعناصر معروفة وموجودة حقيقة لذلك فإنه من المتفق عليه أن كلما كانت خبرات الطفل الموسيقية والتجارب المتوفرة له أكبر كلما كانت فرصته فى الابتكار أكبر ويساعد الابتكار الموسيقى الطفل فى التعبير عن نفسه ويحقق له الرضا النفسى وببرز الابتكار فى عدة أثكال منها

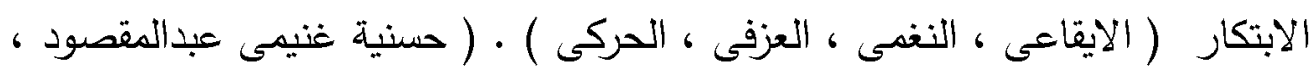

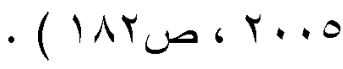

ومن أنواع الابتكار الموسيقى لاى الطفل فى مرحلة رياض الأطفال الغناء

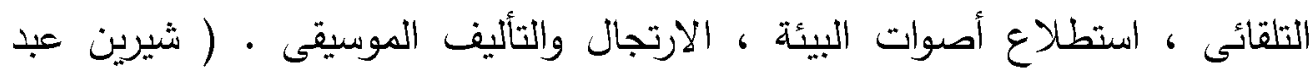

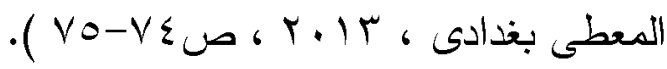

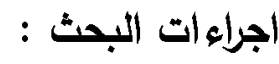
أولا : منهج البحث :

اعتمدت الباحثة في دراستها على المنهج شبه التجريبى ، وقد اختير التصميم التجريبى ذو المجموعة الواحدة عن طريق القياس القبلى والبعدى والتتبعى وذلك

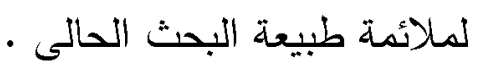
ثانياً : متغيرات البحث : المتغير المستقل : بعض حلقات المسلسل التليفزيونى أجمل الزهور . المتغير التابع : المهار ات الموسيقية . ثالثاً : عينة البحث :

تكونت عينة البحث من أطفال روضة Bright Kids بمحافظة قنا والذين تتراوح أعمارهم من ( 0 : 1 ) سنوات والملتحقين بالمستوى الثانى وعددهم ( • ) ) طفل وطفلة وقد تم اختيار هؤلاء الأطفال بعد تطبيق بطاقة المهارات الموسيقية ـ ـ 
- قائمة ببعض المهارات الموسيقية التى يمكن إكسابها لطفل الروضة . - بطاقة ملاحظة خاصـة ببعض المهارات الموسيقية لطفل الروضة . وفيما يلى توضيع ذلك :

أولا : قائمة ببعض المهارات الموسيقية التى يمكن اكسابها لطفل الروضة : وقد تم إعداد قائمة المهارات الموسيقية بعدة خطوات والتى اتبعت الباحثة فيها ما يلى: 1 الهدف من القائمة : هدفت القائمة إلى تحديد بعض المهارات الموسيقية الرئيسة والفرعية التى يمكن إكسابها من خلا بعض حلقات المسلسل التليزيونى أجمل الزهور لاى أطفال الروضة . r- تحديد مصادر القائمة الخاصة بالمهارات الموسيقية : من خلا الاطلاع على بعض الابحاث والاراسات السابقة المرتبطة بموضوع البحث

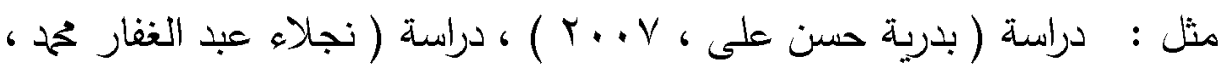

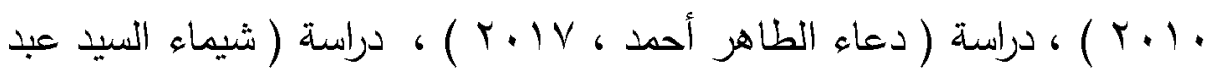

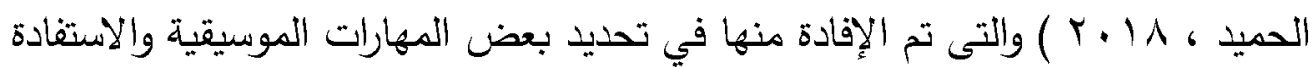

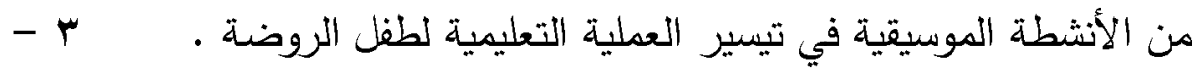
اشتقاق عناصر القائمة وصياغتها : من خلا الخطوات السابقة تم التوصل إلى مجموعة من المهارات الموسيقية وتم تقسيمها إلى بنود أساسية رئيسة وبنود فرعية والتى يمكن إكسابها لاى أطفال مرحلة الروضة وهى : ( الغناء - القصة الموسيقية الحركية - العزف على آلات الباند الإيقاعية - الابتكار ) 
؛ - صياغة مفردات القائمة في صورتها الأولية :

تمت صياغة مفردات القائمة في شكل أفعال قائمة على مهارات موسيقية ( رئيسة ) تندرج تحت كل منها المهارات المرتبطة بها ( فرعية ) لأطفال مرحلة الروضدة . ه - ضبط القائمة الأولية :

من خلال عرض القائمة في صورتها الأولية على مجموعة من السادة المحكمين المتخصصين من أعضاء هيئة التدريس ، ومعلمى التربية الموسيقية بمرحلة رياض

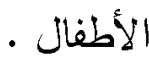

ج- إعداد الصورة النهائية للقائمة :

على ضوه المقترحات التى أبداها السادة المحكمين حول قائمة المهارات الموسيقية وأهميتها النسبية ، وبعد أن تم رصد استجابات السادة المحكمين للأهمية النسبية للمهارات الموسيقية ثم حساب الوزن النسبى لكل مهارة من المهارات الموسيقية والتى تضمنت ( ع ) مهارات رئيسة ، و(ا(Y) مهارة فرعية من المهارات الموسيقية الأعلى : ثانياً أهمية نسبية لاى طفل الروضة . بطاقة الملاحظة الخاصة ببعض المهارات الموسيقية لطفل الروضة : وتعد الملاحظة المباشرة أداه أساسية يمكن من خلالها التعرف على الجدوى الفعلية لأى منهج أو برنامج دراسى ، وذلك وفقاً للخطوات التالية : 1- الاهدف من البطاقة :

تهاف بطاقة الملاحظة إلى التعرف على مدى إكساب بعض المهارات الموسيقية لدى طفل مرحلة الروضة من خلال تدريس الموسيقى باستخدام المسلسل التليفزيونى أجمل الزهور ، والتى تم صياغة بنودها من خلال قائمة المهارات الموسيقية والتى تحددت في المهارات الأساسية التالية : ( مهارة الغناء ، مهارة القصة الموسيقية ، مهارة العزف 


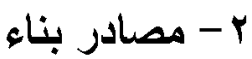

على الآلات الباند الإيقاعية ، مهارة الابتكار ) .

: البطاقة

تم بناء البطاقة في ضوء قائمة المهارات الموسيقي والتى تمثل أهداف الاروس بالبرنامج المقترح ، ومن خلال أهداف التربية الموسيقية الخاصـة بمرحلة رياض الأطفال بالنسبة للجانب الوجدانى ، والاطلاع على بعض الدراسات والبحوث التى تناولت إعداد بطاقة الملاحظة بصفة عامة ، والمهارات الموسيقية بصفة خاصة .

\section{r- صياغة مفردات البطاقة :}

تم مراعاة صياغة مفردات البطاقة بكل دقة وبصيغة واضحة بحيث تتفق مع أهدافها وطبيعتها ، حيث تم الاعتماد في صياغة عناصرها على قائمة المهارات الموسيقية ومن خلال أهداف التربية الموسيقية الخاصة بمرحلة رياض الأطفال ، هذا وقد روعى عدة شروط عند صياغة البطاقة منها : عدم اشتمال كل عبارة على أكثر من أداء ، تبسيط العبارات ووضوحها وقصرها ، العبارة إجرائية حتى يسهل ملاحظتها وقياسها

$$
\text { و أن يكون الفعل في حالة المضارع • صياغة تعليمات البطاقة : }
$$

روعى عند صياغة تعليمات البطاقة أن تكون محددة و واضحة بحيث تيسر إجراء

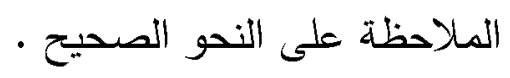

$$
\text { ه- تحكيم البطاقة : }
$$

عرض البطاقة على مجموعة من المحكمين بحيث تسير على الثكل الصحيح وللتأكد من صدقها ، احتواء مفردات البطاقة على الأداء المناسب للمهارات الموسيقية التى تم تحديدها من خلال قائمة المهارات الموسيقية ومن خلا أهداف التربية الموسيقية لمرحلة الروضدة ، مدى وضوح الصياغة السلوكية لمفردات البطاقة ، ملائمة التقدير 
الكمى للبطاقة وإضافة أى ملاحظات يرونها في صالح البطاقة . التجربة

\section{الإستطلاعية وحساب صدق وثبات البطاقة :}

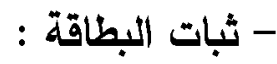

بعد إجراء التعديلات على بطاقة الملاحظة بناءا على آراء المحكمين تم إجراء التجربة الإستطلاعية للبطاقة عن طريق إعادة تطبيق بطاقة المهارات الموسيقية على عينة ضبط الخصائص السيكومترية بعد أسبوعين من التطبيقين الأول وحساب معامل رتباط درجات الأطفال في التطبيق للارجة الكلية وكان معامل الارتباط الكلى البعد 692. ومعامل ارتباط الأول الغناء = الغ 841. البعد الثانى القصة الموسيقية = 752. البعد الثالث العزف = 728. البعد الرابع الابتكار = - البع 811.

وقد تراوحت قيم الفا كرونباخ لمقاييس المهارات الموسيقية من ( 841 ـ - 692. ) مما يدلل علي تحقق قيم ثبات مرتفعة وتمتعها بخصائص سيكومترية تدلل علي صلاحيتها للاستخدام وتحقيق الهذف الذي أعدت من أجله .

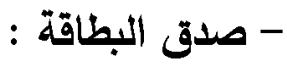

اعتمد حساب صدق بطاقة الملاحظة على صدق المحكمين من خلال عرض

بنود البطاقة على مجموعة من المحكمين من ذوى التخصص حيث تم تعديل البنود التى أتقق المحكمين على تعديلها وتم الاحتفاظ بالبنود التى حصلت على أكثر من . ر وبهذا أصبحت البطاقة في صورتها النهائية صالحة للتطبيق . 
- اختيار عينة البحث نظام المجموعة الواحدة من أطفال الروضة بالمستوى الثانى (

- - تطبيق بطاقة الملاحظة الخاصة بالمهارات الموسيقية تطبيقا قبليا على عينتالبحث. - تدريس البرنامج الموسيقى القائم على بعض حلقات المسلسل التليززيونى أجمل الزهور .

- تطبيق بطاقة الملاحظة الخاصة بالمهارات الموسيقية تطبيقاً بعدياً على عينة البحث .

- تطبيق بطاقة الملاحظة الخاصة بالمهارات الموسيقية تطبيقاً تتعياً على عينة البحث .

خامساً : نتائج البحث وتفسيرها :

\section{النتائج الإحصائية:}

بعد الاطلاع على البحوث وأدبيات البحث العلمي في كيفية تناول النتائج وتفسيرها والطرق الإحصائية المختلفة التي توضح الفروق بين المجموعتين التجربيية والضابطة

في القياسات القبلية والبعدية والتتبعية وكيفية استخدام البرامج الإحصائية بأنواعها المختلفة، حيث قامت الباحثّة باستخدام حزمة البرامج ذات الدلالة الإحصائية للعلوم الاجتماعية Prism وهي أحد إصدارات برنامج SPSS وذلك لحساب كلاً من:

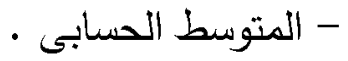

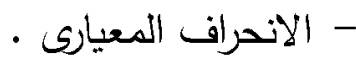


- استخدام اختبار ت لقياس دلالة الفروق بين متوسط الدرجات للمجموعة التجريبية والضابطة على بطاقة الملاحظة الخاصة بالمهارات الموسيقية .

وبتحليل النتائج تبين ما يلي :

أولاً : توجد فروق ذات دلالة إحصائية بين متوسطات درجات الأطفال فى التطبيق القبلى والبعدى لبطاقة ملاحظة المهارات الموسيقية وأبعادها لصالح التطبيق البعدى وتعلل الباحثة ذلك بارتفاع في مستوى أداء الأطفال مجموعة البحث يث زاد متوسط درجات مهارات الغناء بعد التدريب بمقدار 95.667 عن قبل التدريب وكانت هذه

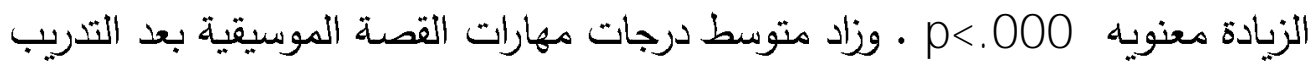
بمقدار 75.877 عن قبل التدريب وكانت هذه الزيادة معنويـ 000<0 م ـ وزاد ايضا متوسط درجات مهارات العزف بمقدار 148.505 عن قبل التدريب وكانت هذه الزيادة

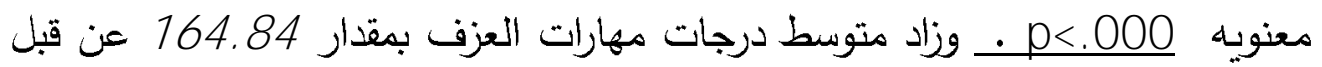
التريب وكانت هذه الزيادة معنويه 000>00 ـ كما زاد متوسط درجات الأطفال لكل المهارات الموسيقية مجتمعه بمقدار 154.038 عن قبل التدربب وكانت هذه الزيادة ايضا معنونيه P<000 · وبذلك يجيب البحث الحالى على السؤال الثانى " ما فاعلية البرنامج الموسيقى القائم على بعض حلقات مسلسل أجمل الزهور لاكتساب بعض المهارات الموسيقية لطفل الروضة ؟ من خلا صحة إثبات الفرض الأول والذى ينص على " توجد فروق ذات دلالة إحصائية بين متوسطات درجات الأطفال فى التطبيق القبلى والبعدى لبطاقة ملاحظة المهارات الموسيقية وأبعادها لصالح التطبيق البعدى " . ثانياً : لا توجد فروق ذات دلالة إحصائية بين متوسطات درجات الأطفال فى التطبيق البعدى الأول والبعدى الثانى ( التتبعى ) لبطاقة ملاحظة المهارات الموسيقية وأبعادها وتعلل الباحثة ذلك بتقارب المتوسط الحسابى للقياس البعدى الأول والثانى ( التتبعى ) 
لمجموعة البحث حيث زاد متوسط درجات مهارات الغناء البعدى الثانى بمقدار 98. عن البعدى الاول وكانت هذه الزيادة غير معنويه 05 05_. وقل متوسط درجات مهارات القصة الموسيقية البعدي الثاني بمقدار 313. عن البعدى الاول وكانت هذه الزيادة غير معنويه p>05 p · بينما قل ايضا متوسط درجات مهارات العزف في الاختبار البعدى الثانى بمقدار 3.042 عن البعدى الاول وكانت هذه الزيادة معنويه P<001 م ـ مقل متوسط درجات مهارات الابتكار في الاختبار البعدى الثانى بمقدار 842.عن الاختبار البعدى الاول وكانت هذه الزيادة غير معنويه 05>05 . كما قل مي متوسط درجات الأطفال لكل المهارات الموسيقية مجتمعه بمقدار 559. عن البعدي الاول وكانت هذه الزيادة ايضا غير معنويه 05 p>p . وهذا ما أكدته دراسة ( ريهام

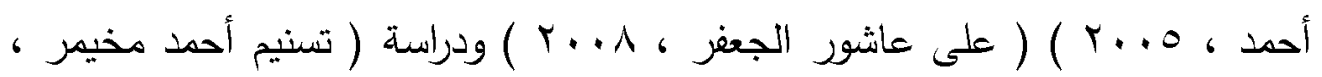

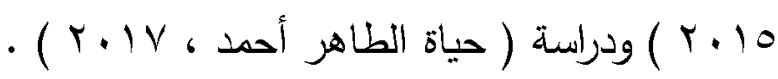
سادساً : التوصيات والبحوث المقترحة : أ - أتوصيات : أن على ضوء ما أسفرت عنه نتائج البحث يوصى بما يلى : 1- تبنى البرنامج الموسيقى القائم على بعض حلقات المسلسل التليفزيونى أجمل الزهور في تدريس مادة التربية الموسيقية لما لها من تأثير فعال في القدرة على اكساب بعض المهارات الموسيقية لطفل الروضة. r- الاستفادة من قائمة المهارات اللازمة لاكتساب المهارات الموسيقية التى تم تحديدها في وضع صياغة الأنشطة الموسيقية بما يحقق تلك المهارات . r- ضرورة مراعاء الأهداف التربوية التى تسعى التربية الموسيقية إلى تحقيقها في

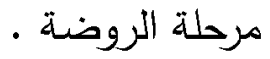


ع- ضرورة تواصل الروضة مع الأسرة لفهم طبيعة البرامج المقدمة لأبنائهم وتوضيح دورها في اكتساب بعض المهارات المختلفة لليهم . ه- إعداد دورات تدربية تربوية موسيقية لإرشاد وتوجيه المعلمات على كيفية استخدام الوسائل والطرق والأساليب التعليمية الحديثة في التعلم لما يخدم طفل مرحلة الروضة في جميع نواحيه المختلفة .

T- تشجيع المعلمات على استخدام التقنيات الحديثة في التدري بما يتماشى مع تطورات العصر وتلبية احتياجات طفل الروضة . V- ضرورة تشجيع الأطفال على التفاعل الإيجابى والمشاركة في المواقف التعليمية والخروج عن الخجل والإنطواء عن طريقة البرنامج الموسيقى القائم على بعض حلقات مسلسل أجمل الزهور بما يزيد من ثقة الطفل في نفسه . ^- تفعيل البرنامج الموسيقى القائم على بعض حلقات مسلسل أجمل الزهور في مؤسسات رياض الأطفال الحكومية والخاصة لتكون احد الطرق الفعالة في تدريس مادة التربية الموسيقية .

9- إعداد كتيبات تحتوى على الوسائل التعليمية والطرق والأساليب والاستراتيجيات الحديثة في التعلم حتى يستعين بها المعلمون في التعليم والتعلم . • 1- إعداد اسطوانات وفديوهات تعليمية تهتم بتنمية المهارات الموسيقية الخاصة بمرحلة الروضة . - مبة 11 - عقد بعض المؤتمرات العربية والعالمية التى تهتم بتنمية المهارات الموسيقية الخاصة بمرحلة الروضة . - مل 
Y ا - الاهتمام بتخطيط وتصميم مناهج التزبية الموسيقية لطفل مرحلة الروضة على أسس علمية سليمة

rا - توفير الإمكانيات والتجهيزات اللازمة للتمكن من تتفيذ أنشطة التربية الموسيقية داخل المؤسسة التعليمية لما لذلك من تحقيق للأهداف التربوية المرجوة . ب- البحوث المقترحة : امتداد للبحث الحالى يقترح إجراء البحوث التالية :

ا ـ اجراء دراسات مماثلة للدراسة الحالية على المراحل تعليمية مختلفة .

r. دور برامج الأطفال التليزيونية في اكتساب بعض المهارات الموسيقية

$$
\text { والاجتماعية لأطفال الروضة . }
$$

r. أثر استخدام برامج الأطفال التليفزيونية في تنمية المهارات الموسيقية وأثرها على التذوق الموسيقى لاى طفل الروضة . ع. فاعلية برنامج قائم على برامج الأطفال التليفزيونية في تحقيق معايير ومؤشرات التربية الموسيقية لأطفال مرحلة الروضة .

ه. أثر استخدام برامج الأطفال التليفزيونية في تنمية بعض المفاهيم الموسيقية

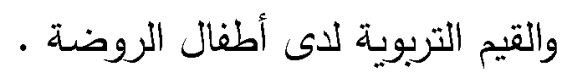

ج. الاستفادة من الأنشطة الموسيقية في تنمية الوعى الوطنى والاينى لاى أطفال

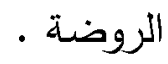

V. أثر استخدام الأنشطة الموسيقية في تنمية التفكير الناقد والذكاء الوجدانى لاى

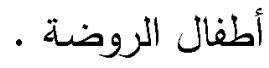




\section{2) \\ أولا : المراجع العربية :}

إبراهيم الخطيب وآخرون (1 + . . . . ، أثر وسائل الإعلام على الطفل ، مكتبة دار

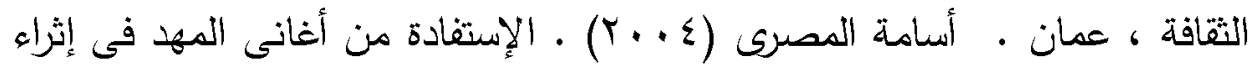
الأنشطة الموسيقية لمرحلة رياض الأطفال ، رسالة ماجستير غير منشورة ، كلية

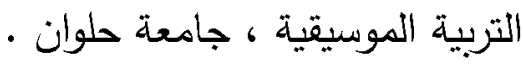

آمال حسين خليل (0. ب) ـ الإبداع واستراتيجيات تدريس التربية الموسيقية ، دار الثقافة العلمية ، الإسكندرية .

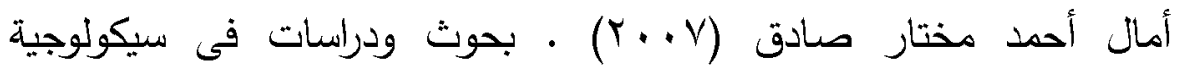
الموسيقى والتربية الموسيقية ، مكتبة الأنجلو المصرية ، القاهرة ـ دور الموسيقى إيناس السيد محمد ناسه (9 . . r) ـ الإعلام المرئى وتتمية ذكاءات الطفل العربى ، دار الفكر ، عمان ، طا. ادوارد ستاشيف ، رودى بريثز ( د.ت ) · براهج التليزيون : إنتاجها وإخراجها ،

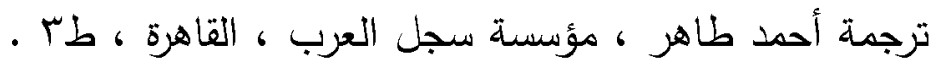

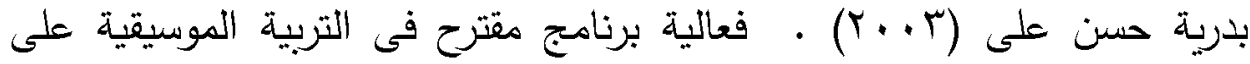
تعديل بعض العادات السلوكية غير المرغوب فيها لدى أطفال الرياض فئ ، رسالة ماجستير ، قسم المناهج وطرق التدريس ، كلية التربية بقنا ، جامعة جنوب الوادى 
بدرية حسن علي (Y. . . (Y). فعالية استراتيجية التعلم التعاوني في تتمية بعض المفاهيم والمهارات الموسيقية والوعي القومي للي تلاميذ المرحلة الإعدادية ، رسالة دكتوراة ، كلية تربية نوعية ، جامعة جنوب الوادي .

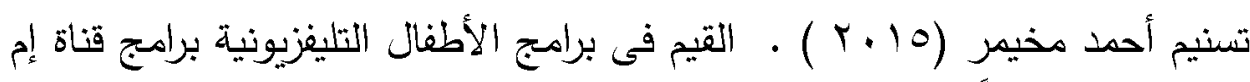

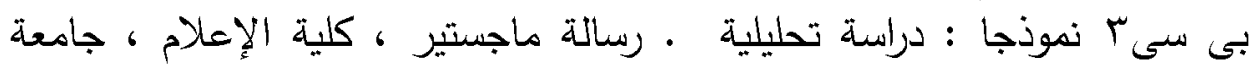

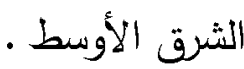
جيلان أحمد عبد القادر (1 . . . . الموسيقى والطفل ، المتحدة للطباعة ، القاهر5 حسنية غنيمى عبد المقصود (0 ( ب) . دراسات وبحوث فى علم نفس الطفل ، دار عالم الكتب ، القاهر5 ، طا ـ الم حياة الطاهر أحمد (Y.IV) . دور برامج الأطفال التليززيونية فى دعم القيم التربوية والسلوكية : دراسة وصفية تحليلية بالتطبيق على برنامج "قطار الزهور" بقناة الثروق الفضائية ، رسالة ماجستير ، كلية علوم الإتصال ، جامعة الجزيرة.

ديو بولا فان داليه (19V9) ." مناهج البحث في التربية وعلم النفس " ، القاهرة دماء

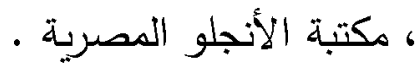

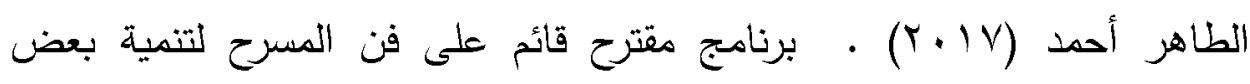
المهارات الموسيقية والاجتماعية لاى طفل الروضة ، رسالة ماجستير ، كلية

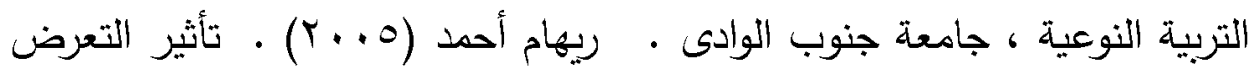

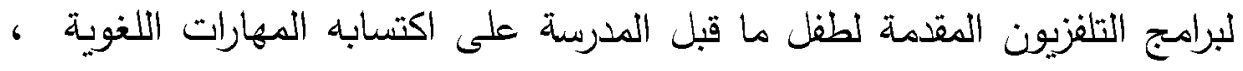
رسالة ماجستير ، قسم الإذاعة ، كلية الإعلام ، جامعة القاهر5 ، مصر ل 


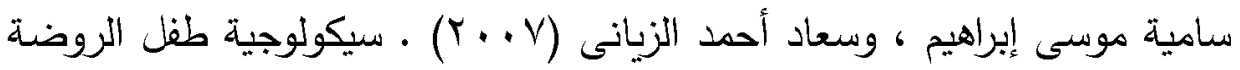
بين المناهج ونظريات التعلم والأنشطة الموسيقية ، دار الفكر العربى ، القاهرة ، $.1 \mathrm{~b}$

سعاد عبد العزيز نجلة ، صباح يوسف أحمد (r ( †) • التعبير الموسيقى الحركى

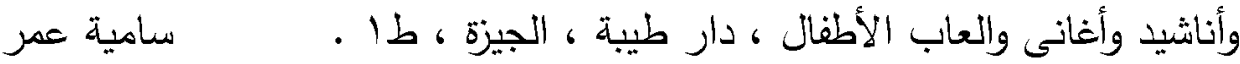

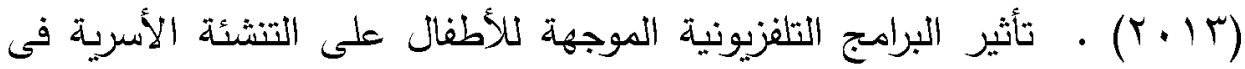
المجتمع الجزائرى : دراسة ميدانية ، قسم العلوم الاجتماعية ، كلية العلوم الإنسانية شيرين عبد والاجتماعية ، جامعة محمد خضر ، بسكرة .

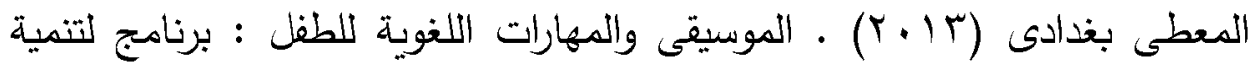

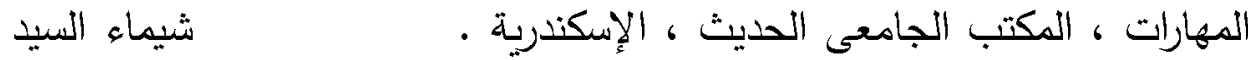

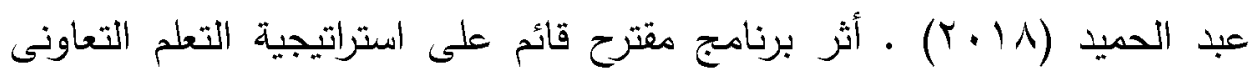
لتمية بعض المهارات الموسيقية والاجتماعية لاى تلاميذ المرحلة الإبتدائية . ،

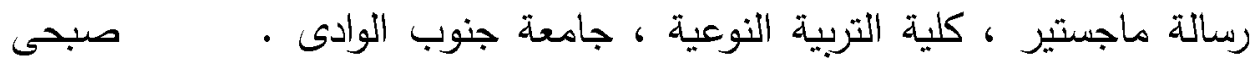

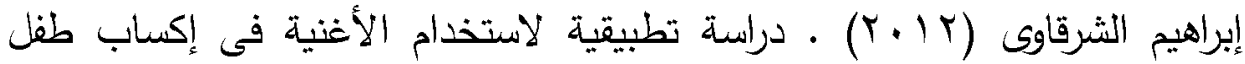
الروضة مفاهيم جديدة ، دراسات - العلوم الإنسانية والاجتماعية ، عمادة البحث

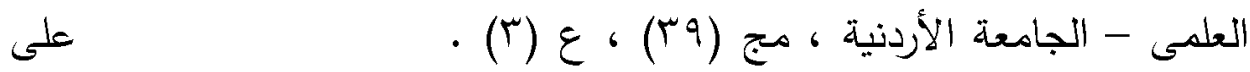

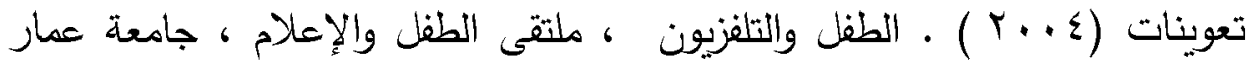
على ثليجى ، الأغواط ، الجزائر عاشور الجعفر (1 . . r) • " البرامج الفضائية لاى عينة من الأطفال بدولة الكويت

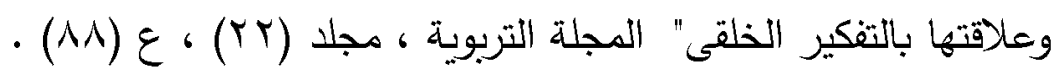

فؤاد أبو حطب ، أمال صادق (1 (Y) ) . علم النفس التربوى ، مكتبة الأنجلو المصرية ، القاهرة . كرم شلبى (9AV ( ) . فن الكتابة للراديو والتلفزيون ، دار

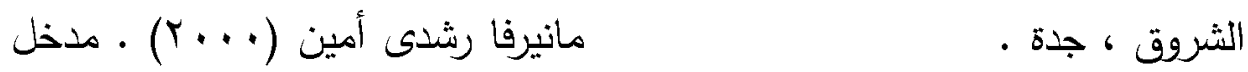


إلى مهارات التدرس ومعلم التربية الموسيقية ، مكتبة الأنجلو المصرية ، القاهرة .

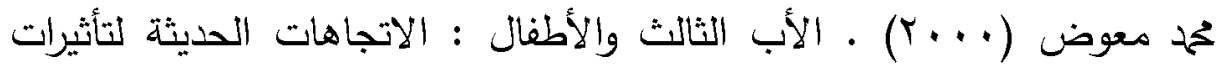

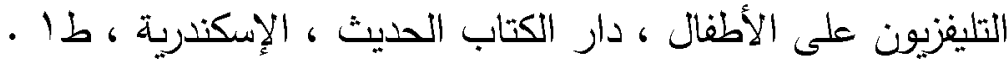

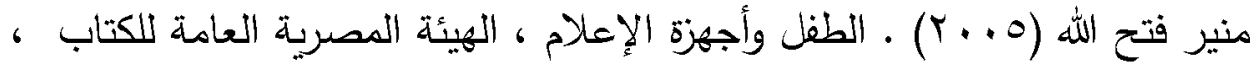

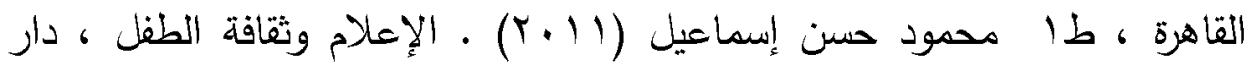
الفكر العربى ، القاهرة ، طاه

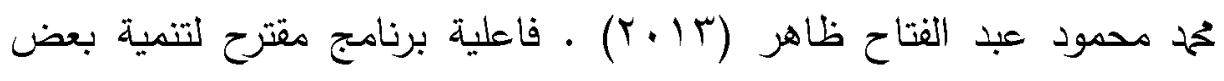
مهارات التربية الموسيقية فى ضوه المعايير الدولية لدى طلبة الصف التاسع الأساسى بغزة ، كلية التربية ، جامعة الأزهر ، غزة ، فلسطين.

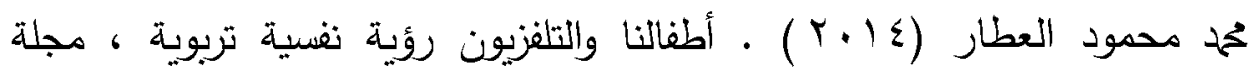

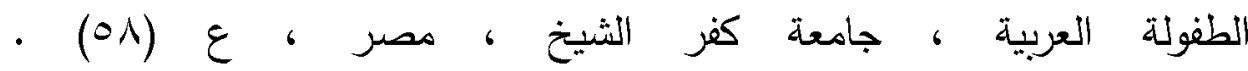

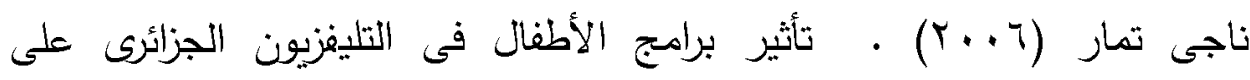
معلومات تلاميذ الطور الثانى من التعليم الأساسى : دراسة ميدانية فى ولاية

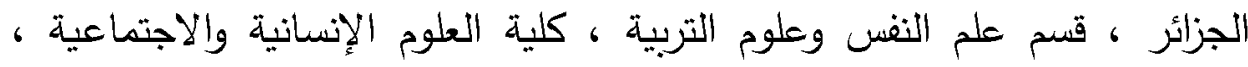
· جامعة الجزائر

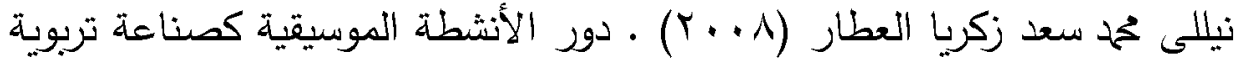
آمنة للحد من بعض سلوكيات الضوضاء لاى طفل الروضة ، المؤتمر العلمى

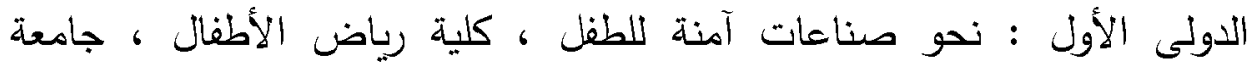

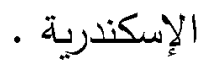

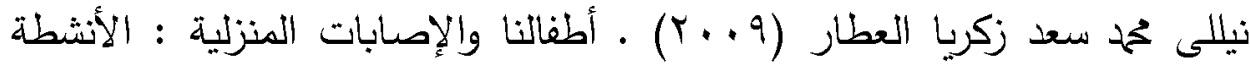

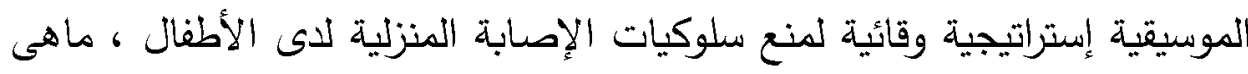

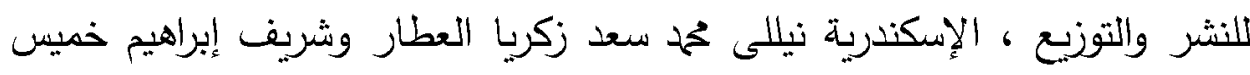

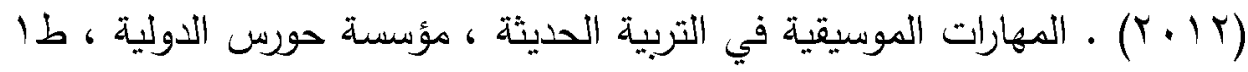


نجلاء عبد الغفار محمد

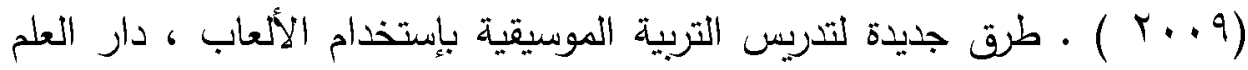

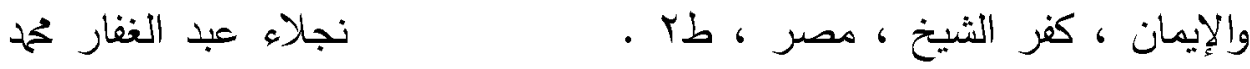

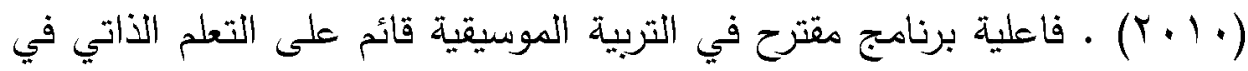
التحصيل المعرفي وتنمية بعض المهارات الموسيقية والتذوق الموسيقي للى طالبات شعبة رياض الأطفال بكلية التربية بسوهاج • رسالة دكتوراه غير منشورة

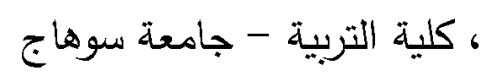

نرمين صبرى شحاته كيرلس (Y (Y) ) فاعلية برنامج مقترح لتنمية بعض

المهارات الموسيقية لاى طفل الروضة فى ضوه بعض معايير الجودة الثاملة ،

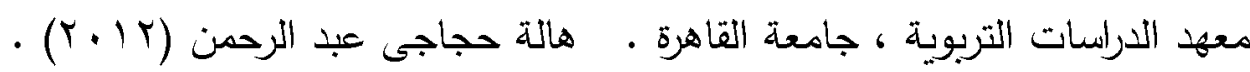
برامج الأطفال التليزيونية وآتارها التربوية دراسة نظرية وميدانية ، دار العلم هانى

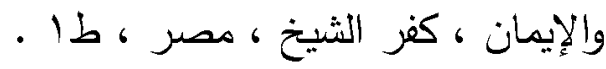

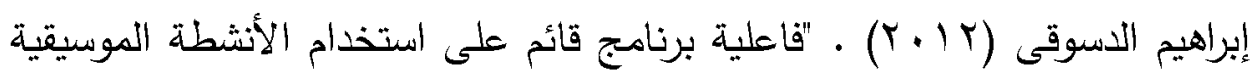

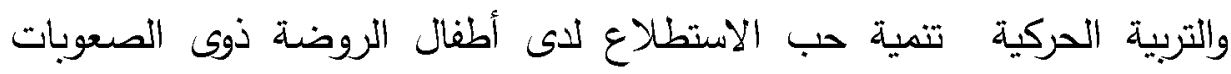

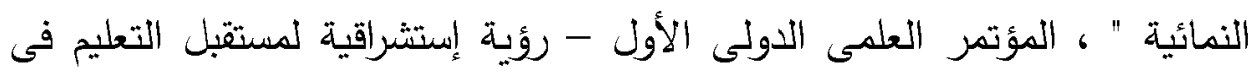
مصر والعالم العربى فى ضوه التغيرات المجتمعية المعاصرة ، كلية التربية ومركز

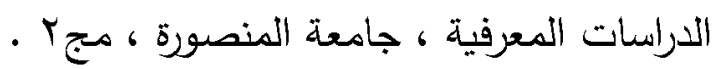

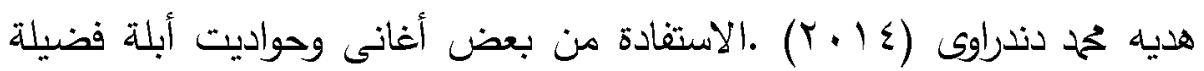
فى تنمية بعض القيم التربوية وبعض المفاهيم الموسيقية لطفل مرحلة رياض

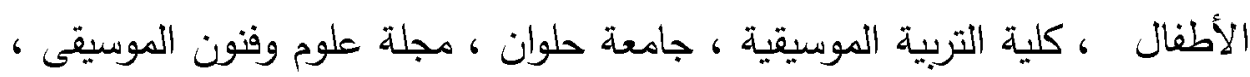

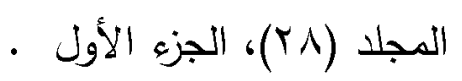
هيثم يحيى خواجة (ع + r) ـ أدب الأطفال بين النظرية والتطبيق ، وزارة الثقافة وديع

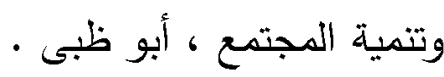

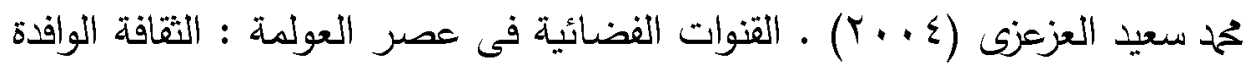
وسلطة الصورة ، منثورات وزارة الثقافة ، صنعاء . 


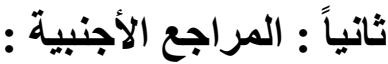

Stephen,k. and Stewart, k. (2000): Children and Multidisciplinary Approaches, CBGS and Graat Publisher (on line) Availailable :http : books. Google . com Hallam, S. (2001). Learners: Their Characteristics and Development in Mapping Music Education Research in the UK. London: BERA.

Grimes,T. \& Bergen,L . \&Nichols, K.Vernberg, E.\&Fonagy, P,(2004)Is Psychopathology the key to understanding why some children Become Aggressive When They Are Exposed to violent television programming ? Human communication Research,v30 n2 p153-181 Apr .

\section{ثالثاً : المراجع الإكترونية :}

https://www.elcinema.com/work/2035835/

http://www.dostor.org / 